\title{
CORRIGENDA
}

\section{Translocation $t(4 ; 14)$ retains prognostic significance even in the setting of high-risk molecular signature}

WJ Chng, WM Kuehl, PL Bergsagel and R Fonseca

Leukemia (2008) 22, 462; doi:10.1038/sj.leu.2405089

Corrigendum to: Leukemia advance online publication, 6 September 2007; doi:10.1038/sj.leu.2404934

Since the publication of the above letter online, the authors have noticed a couple of errors in the identification of high-risk patients affecting the survival comparison.

First, the 70-gene, rather than the 17-gene, molecular signature was applied to the Mayo data set, using the expression of only probe sets that have been represented on the U133A Affyemtrix chip. The survival of the high-risk patients $(n=10)$ was only 12.5 months compared to 55.1 months for the other patients (log-rank $P=0.0009)$.

Second, there was also an error in calculating the 17-gene index for the UAMS cohort. Using the correct formula (200638_

\begin{abstract}
s_at $\times 0.283)-(1557277$ a_at $\times 0.296)-\left(200850 \_\right.$s_at $\left.\times 0.208\right)$ $+(201897$ s_at $\times 0.314)-\left(202729 \_s \_a t \times 0.287\right)+(203432$ at $\times 0.251)+\left(204016 \_\right.$at $\left.\times 0.193\right)+\left(205235 \_s \_\right.$at $\left.\times 0.269\right)+\left(206364 \_\right.$ at $\times 0.375)+\left(206513 \_\right.$at $\left.\times 0.158\right)+\left(211576 \_\right.$s_at $\left.\times 0.316\right)+$ $\left(213607 \_\right.$x_at $\left.\times 0.232\right)-\left(213628 \_\right.$at $\left.\times 0.251\right)-\left(218924 \_\right.$s_at $\left.\times 0.23\right)$ $-\left(219918 \_s \_\right.$at $\left.\times 0.402\right)+\left(220789 \_\right.$s_at $\left.\times 0.191\right)+(242488$ at $\times 0.148)-10.28$, high-risk patients with $\mathrm{t}(4 ; 14)(n=8)$ have significantly shorter survival than high-risk patients without $\mathrm{t}(4 ; 14)(n=33)$, median overall survival of 11.6 months vs 27.3 months, log-rank $P=0.005$.
\end{abstract}

In essence, the conclusions drawn from the original letter remain the same. We apologize for any inconvenience caused.

\section{Addition of intravenous iron to epoetin beta increases hemoglobin response and decreases epoetin dose requirement in anemic patients with lymphoproliferative malignancies: a randomized multicenter study}

M Hedenus, G Birgegård, P Näsman, L Ahlberg, T Karlsson, B Lauri, J Lundin, G Lärfars and A Österborg

Leukemia (2008) 22, 462; doi:10.1038/sj.leu.2405094

Correction to: Leukemia (2007) 21, 627-632. doi:10.1038/sj.leu.2404562

Since the publication of the above paper, the authors have detected a minor error that has no impact on their conclusion.

Please note that the last sentence on page 629 'Corresponding mean total doses for the ITT population were
532000 and 629000IU ( $P=0.059)$, respectively.' should be corrected to 'Corresponding mean total doses for the ITT population were 483000 and $597000 \mathrm{IU}(P=0.060)$, respectively.'

The authors apologize for any inconvenience caused. 